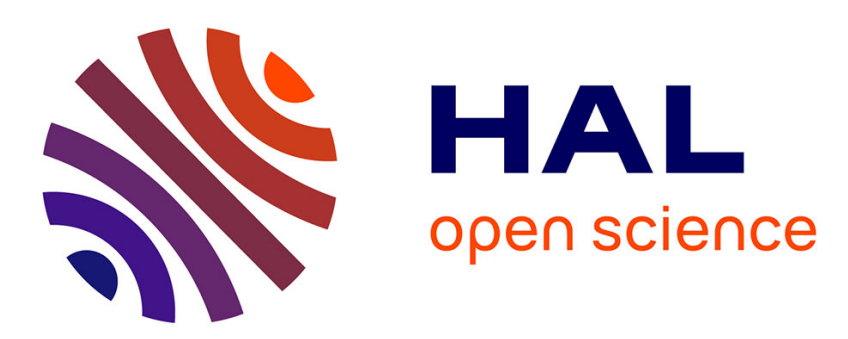

\title{
Generalization of the area method for the determination of the parameters of a non-ideal solar cell \\ B. Arcipiani
}

\section{To cite this version:}

B. Arcipiani. Generalization of the area method for the determination of the parameters of a non-ideal solar cell. Revue de Physique Appliquée, 1985, 20 (5), pp.269-272. 10.1051/rphysap:01985002005026900 . jpa-00245331

\section{HAL Id: jpa-00245331 https://hal.science/jpa-00245331}

Submitted on 1 Jan 1985

HAL is a multi-disciplinary open access archive for the deposit and dissemination of scientific research documents, whether they are published or not. The documents may come from teaching and research institutions in France or abroad, or from public or private research centers.
L'archive ouverte pluridisciplinaire HAL, est destinée au dépôt et à la diffusion de documents scientifiques de niveau recherche, publiés ou non, émanant des établissements d'enseignement et de recherche français ou étrangers, des laboratoires publics ou privés. 
Classification

Physics Abstracts

$84.60 \mathrm{~J}-72.40$

\title{
Generalization of the area method for the determination of the parameters of a non-ideal solar cell
}

\author{
B. Arcipiani \\ E.N.E.A. $\left({ }^{+}\right)$, c/o Istituto Donegani, via Nuova delle Brecce 150, 80147 Napoli, Italy
}

(Reçu le 26 septembre 1984, révisé le 21 décembre, accepté le 11 février 1985)

\begin{abstract}
Résumé. - L'équation de la courbe courant-tension d'une cellule photovoltaïque, dont les résistances série et parallèle sont finies, a été ramenée à une forme explicite au moyen d'une rotation des coordonnées. Il s'ensuit que l'aire en dessous de la courbe peut être calculée de façon analytique précise pour une photopile réelle. En substituant dans l'expression analytique l'aire évaluée numériquement à partir de la courbe expérimentale, il est possible de déterminer, par la méthode proposée, la valeur de résistances série et parallèle ainsi que celle du facteur d'idéalité des cellules solaires.
\end{abstract}

\begin{abstract}
The equation of the current-voltage characteristic of a non-ideal solar cell, with finite series and shunt resistances, was reduced to explicit form by means of a suitable rotation of coordinates. Thus the area under the characteristic curve could be calculated in analytical form for realistic models of the cell. Substituting in the new formula the area numerically computed from the experimentally measured curve, there appears the possibility of extending the so called area method to the determination of the quality factor and the series and shunt resistances of the cell.
\end{abstract}

\section{Introduction.}

The electrical operation of a solar cell under illumination is usually described by an equivalent circuit having one or more diodes in parallel with a current generator and a load; correspondingly, its currentvoltage characteristic is analytically represented by one or more well known exponentials. For a nonideal cell, i.e. one whose series resistance and shunt conductance are different from zero, the above models give rise to an equation for the characteristic which cannot be explicitly solved either for the current or the voltage. This fact is of hindrance in the study of several properties of the cell, e.g. when one needs to analytically evaluate the area under its characteristic curve.

Only when the shunt resistance is regarded as infinite, the one-exponential (finite series resistance) equation of the characteristic is explicitly solvable for the voltage in terms of the current thus easily providing an analytical expression for the area by

$\left(^{+}\right)$Italian National Committee for Research and Development of Nuclear and Alternative Energies. straightforward integration. This approximate formula was recently used in relation to the so called area method for the determination of the series resistance of a solar cell [1].

With the aim of extending that method to more realistic situations, we report in the present paper a novel procedure which allows to work out a rigorous analytical expression for the area under the characteristic curve of a non-ideal solar cell even in the most general case of a multi-exponentials equation. The goal is attained by first performing a suitable rotation of the coordinate axes in the current-voltage plane; this trick brings forward, perhaps unexpectedly, an equation for the characteristic which is solvable with respect to one of the variables and therefore, when properly integrated, yields the sought for formula.

Moreover, although we do not have at present the possibility of experimentally verifying it, we suggest an approach which, by applying this new formula for the area, might lead to the determination of the series and shunt resistances and the diode quality factor of the solar cell from measurements of its characteristic at different levels of illumination. 


\section{Equation of the solar cell characteristic after rota- tion of the coordinate axes.}

The one-diode model for a non-ideal solar cell yields (Fig. 1) the following equation for the current (I)voltage $(V)$ characteristic under illumination

$$
\begin{aligned}
I=I_{\mathrm{s}}\left\{\exp \left[\frac{Q}{n K T}(V-r I)\right]-1\right\} & - \\
& -I_{\mathrm{L}}+\frac{V-r I}{R},
\end{aligned}
$$

where $I_{\mathrm{L}}, I_{\mathrm{s}}, n, r, R, Q, K, T$ denote, respectively, the light generated current, diode dark saturation current, diode quality factor, series resistance, shunt resistance, proton charge, Boltzmann constant and absolute temperature. In the following we set $\frac{K T}{Q}=\gamma(T)$, [volt], and introduce the shunt conductance $g=R^{-1}$.

Reversing the sign of the current thus displaying the characteristic in the first, instead of the fourth, quadrant, the above equation becomes

$$
I=I_{\mathrm{L}}+I_{\mathrm{s}}-I_{\mathrm{s}} \cdot \exp \left[\frac{1}{n \gamma}(V+r I)\right]-g(V+r I) .
$$

The intercepts of this curve with the current and voltage axes are, respectively, the short-circuit current $\left(I_{\text {sc }}\right)$ and the open-circuit voltage $\left(V_{\text {oc }}\right)$; these are given by

$$
\begin{gathered}
I_{\mathrm{sc}}=(1+r g)^{-1}\left[I_{\mathrm{L}}+I_{\mathrm{s}}-I_{\mathrm{s}} \cdot \exp \left(\frac{r I_{\mathrm{sc}}}{n \gamma}\right)\right] \\
I_{\mathrm{L}}+I_{\mathrm{s}}-I_{\mathrm{s}} \cdot \exp \left(\frac{V_{\mathrm{oc}}}{n \gamma}\right)-g V_{\mathrm{oc}}=0 .
\end{gathered}
$$

Let us define the new adimensional variables

$$
x=V / V_{\mathrm{oc}} ; y=I / I_{\mathrm{sc}} .
$$

Then equation (1) takes on the following form in the $(x, y)$ plane

$y=j_{\mathrm{L}}+j_{\mathrm{s}}-j_{\mathrm{s}} \cdot \exp (p x+q y)-u(p x+q y)$,

where we have used the adimensional parameters :

$$
\begin{aligned}
j_{\mathrm{L}} & =I_{\mathrm{L}} / I_{\mathrm{sc}} ; \quad j_{\mathrm{s}}=I_{\mathrm{s}} / I_{\mathrm{sc}} ; \quad p=V_{\mathrm{oc}} / n \gamma ; \\
q & =r I_{\mathrm{sc}} / n \gamma ; \quad u=n \gamma g / I_{\mathrm{sc}} .
\end{aligned}
$$

Due to the transformation (3), the characteristic represented by equation (4) cuts the $(x, y)$ axes in two points of unit coordinates (Fig. 2). This condition gives the relations

$$
\begin{aligned}
& j_{\mathbf{L}}+j_{\mathrm{s}}-u q-j_{\mathrm{s}} \cdot \exp (q)=1 \\
& j_{\mathbf{L}}+j_{\mathrm{s}}-u p-j_{\mathbf{s}} \cdot \exp (p)=0
\end{aligned}
$$

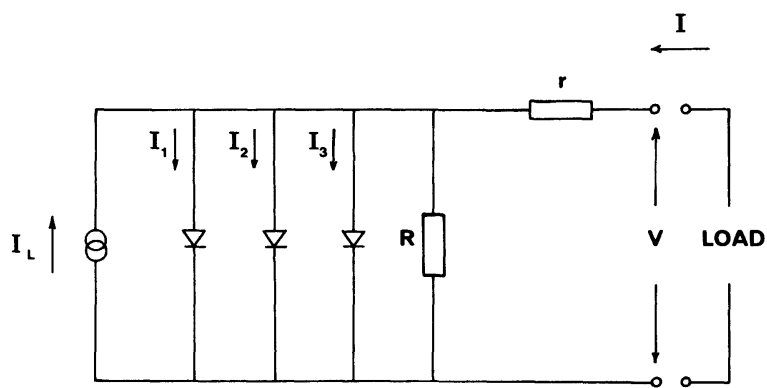

Fig. 1. - Multi-diode model of the equivalent circuit of a solar cell, with series $(r)$ and shunt $(R)$ resistances.

Now we introduce (Fig. 2) the coordinate system $(X, Y)$ obtained through a counterclockwise rotation of the $(x, y)$ axes by an angle $\alpha$, such that

$$
\begin{gathered}
\sin \alpha=q / h ; \quad \cos \alpha=p / h ; \\
h=\left(p^{2}+q^{2}\right)^{1 / 2} .
\end{gathered}
$$

It is well known that such coordinate systems are related to each other by the transformation equations

$$
\begin{aligned}
& x=\frac{1}{h}(p X-q Y), \\
& y=\frac{1}{h}(q X+p Y) .
\end{aligned}
$$

Substituting equations (8) in equation (4) and solving for $Y$, one gets the equation of the characteristic in the $(X, Y)$ plane

$Y=\frac{h}{p}\left[j_{\mathrm{L}}+j_{\mathrm{s}}-\left(u h+\frac{q}{h}\right) X-j_{\mathrm{s}} \exp (h X)\right]$.

We have thus found a coordinate system with respect to which the characteristic curve is represented by one variable as an explicit function of the other. One can easily check that equation (9) is indeed satisfied by the coordinates of points A and B (Fig. 2). In fact,

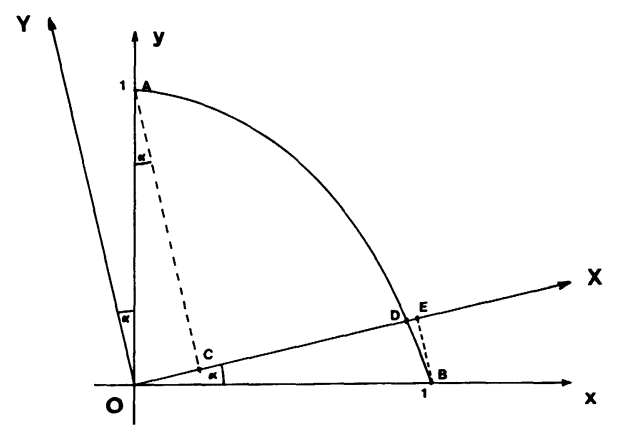

Fig. 2. - Typical characteristic curve of a solar cell in adimensional form. When referred to $(x, y)$ axes this curve is analytically expressed by equation (4) of text; when referred to $(X, Y)$ axes it takes on the explicit form of equation (9) of text. 
either from the transformation equations (8) or directly from the figure, one has for point $\mathrm{A}(x=0, y=1$; $X=\sin \alpha, Y=\cos \alpha)$ and for point $\mathrm{B}(x=1, y=0$; $X=\cos \alpha, Y=-\sin \alpha$ ). Substituting in equation(9) the $(X, Y)$ coordinates of point $\mathrm{A}$ and, in turn, of point $B$, and simplifying one gets, respectively, the first and the second of equations (6).

The procedure carried out to attain equation (9) applies also for the many-diodes model of the equivalent circuit. In this case the equation of the $(I, V)$ characteristic, corresponding to equation (1), is [2]

$$
\begin{array}{r}
I=I_{\mathrm{L}}-\sum_{i=1}^{N} I_{\mathrm{s} i}\left\{\exp \left[\frac{1}{n_{i} \gamma}(V+r I)\right]-1\right\}- \\
-g(V+r I),
\end{array}
$$

where $I_{\mathrm{si}}$ and $n_{i}$ are the dark saturation current and the quality factor of the $i$-th diode, and $N$ is the total number of diodes.

It is convenient to set $n_{1}=n$, and $f_{i}=n_{i} / n$, ( $i=1,2, \ldots, N$; thus $f_{1}=1$ ).

If now one performs all the same steps as before, one gets the equation of the characteristic in the $(X, Y)$ plane

$$
\begin{aligned}
& Y=\frac{h}{p}\left[j_{\mathrm{L}}+\sum_{i=1}^{N} j_{s i}-\sum_{i=1}^{N} j_{s i}\right. \exp \left(h X / f_{i}\right)- \\
&-(u h+q / h) X],
\end{aligned}
$$

where $j_{\mathrm{si}}=I_{\mathrm{si}} / I_{\mathrm{sc}}$ and the short-circuit current and open-circuit voltage are, of course, to be obtained from equation $\left(1^{\prime}\right)$ according to definition. In particular, the equations corresponding to equations (6), satisfied by $I_{\mathrm{sc}}$ and $V_{\mathrm{oc}}$ in the adimensional parameter form, are

$$
\begin{aligned}
& j_{\mathrm{L}}-u q-\sum_{i=1}^{N} j_{s i}\left[\exp \left(q / f_{i}\right)-1\right]=1 ; \\
& j_{\mathrm{L}}-u p-\sum_{i=1}^{N} j_{s i}\left[\exp \left(p / f_{i}\right)-1\right]=0 .
\end{aligned}
$$

\section{Analytical expression for the area.}

The area $A$ bounded by the current-voltage characteristic of the solar cell and the $(I, V)$ axes is

$$
A=\int_{0}^{V_{\mathrm{oc}}} I(V) \mathrm{d} V .
$$

Applying the coordinate transformation of equations (3) one has

$$
A=V_{\mathrm{oc}} \cdot I_{\mathrm{sc}} \int_{0}^{1} y(x) \mathrm{d} x=V_{\mathrm{oc}} \cdot I_{\mathrm{sc}} \cdot A_{\mathrm{a}},
$$

where $A_{\mathrm{a}}$ is the area bounded by the characteristic in adimensional form [equation (4), Fig. 2] and the $(x, y)$ axes. We have to calculate this latter knowing the explicit equation of the curve with respect to the $(X, Y)$ axes [Eq. (9)]. From figure 2 one easily writes

$$
\begin{aligned}
A_{\mathrm{a}}=T(\mathrm{OAC})+ & \int_{X_{\mathrm{C}}}^{X_{\mathrm{D}}} Y(X) \mathrm{d} X+ \\
& +T(\mathrm{OBE})+\int_{X_{\mathrm{D}}}^{X_{\mathrm{E}}} Y(X) \mathrm{d} X,
\end{aligned}
$$

where $X_{\mathrm{C}}, X_{\mathrm{D}}, X_{\mathrm{E}}$ are the $X$ coordinates of points $\mathrm{C}$, $\mathrm{D}, \mathrm{E}$, respectively, and $T$ 's are the areas of the two triangles indicated. Notice that the last integral above is negative since for values of $X \in\left(X_{\mathrm{D}}, X_{\mathrm{E}}\right)$ the curve $Y(X)$ is below the $X$ axis. Moreover one has $T(\mathrm{OAC})=T(\mathrm{OBE})=X_{\mathrm{A}} Y_{\mathrm{A}} / 2=\sin \alpha \cdot \cos \alpha / 2=$ $p q / 2 h^{2}$ and $X_{\mathrm{C}}=X_{\mathrm{A}}=\sin \alpha=q / h ; X_{\mathrm{E}}=X_{\mathrm{B}}=$ $\cos \alpha=p / h$. Calculating from equation (9) $\int Y(X) \mathrm{d} X$ $=F(X)$, equation (11) yields

$$
A_{\mathrm{a}}=p q / h^{2}+F(p / h)-F(q / h) .
$$

Inserting this in equation (10), carrying out the calculations and simplifying by means of the relation

$$
j_{\mathrm{s}}[\exp (p)-\exp (q)]=1+u(q-p)
$$

that follows from subtraction of equations (6), returning finally to the original parameters, we obtain for the area in the one-exponential model of the characteristic

$$
\begin{aligned}
A= & \left(I_{\mathrm{L}}+I_{\mathrm{s}}\right)\left(V_{\mathrm{oc}}-r I_{\mathrm{sc}}\right)+ \\
& +I_{\mathrm{sc}}(1+g r)\left(r I_{\mathrm{sc}} / 2-\gamma n\right)+V_{\mathrm{oc}} g\left(\gamma n-V_{\mathrm{oc}} / 2\right) .
\end{aligned}
$$

Analogous calculations using equation $\left(9^{\prime}\right)$, after suitable simplifications based on subtracting equations $\left(6^{\prime}\right)$, lead to the area in the multi-exponentials model of the characteristic

$$
\begin{aligned}
A=\left(I_{\mathrm{L}}+\sum_{i=1}^{N} I_{\mathrm{si}}\right)\left(V_{\mathrm{oc}}-r I_{\mathrm{sc}}\right)+I_{\mathrm{sc}} & (1+g r)\left(r I_{\mathrm{sc}} / 2-\gamma n\right)+ \\
& +V_{\mathrm{oc}} g\left(\gamma n-V_{\mathrm{oc}} / 2\right)+\gamma \sum_{i=2}^{N} I_{\mathrm{si}}\left(n_{i}-n\right)\left[\exp \left(r I_{\mathrm{sc}} / \gamma n_{i}\right)-\exp \left(V_{\mathrm{oc}} / \gamma n_{i}\right)\right] .
\end{aligned}
$$


This latter expression reduces to equation (12) if only one diode is present $\left(I_{\mathrm{s} i}=0\right.$, for $i=2,3, \ldots, N$; $\left.I_{\mathrm{s} 1}=I_{\mathrm{s}}\right)$. Moreover, if the shunt resistance is regarded as infinite, one recovers from equation (12) the formula for the area employed in [1].

\section{Determination of the parameters of a solar cell.}

The one-diode model of the cell provides a simple yet reasonably accurate picture of its operation. The newly developed formula for the area in this model suggests a generalized version of the area method which might yield, besides the series resistance, also the shunt resistance and the diode quality factor.

In equation (12) for the area one may neglect the product $g r$ with respect to unity as the series resistance and shunt conductance are reasonably small in a realistic solar cell. Moreover let us also use the commonly accepted [1] approximation $I_{\mathrm{s}} \ll I_{\mathrm{L}}$ and $I_{\mathrm{sc}} \approx I_{\mathrm{L}}$. Then from equation (12)

$$
\begin{aligned}
\frac{I_{\mathrm{sc}} \cdot V_{\mathrm{oc}}-A}{I_{\mathrm{sc}} \cdot V_{\mathrm{oc}}} & =\rho=\left(I_{\mathrm{sc}} / 2 V_{\mathrm{oc}}\right) r+ \\
& +\left(\gamma / V_{\mathrm{oc}}\right) n+\left(V_{\mathrm{oc}} / 2 I_{\mathrm{sc}}\right) g-\left(\gamma / I_{\mathrm{sc}}\right) g n .
\end{aligned}
$$

If one experimentally measures the $(I, V)$ characteristic of the cell, including in particular the shortcircuit current and the open-circuit voltage, and computes the area under the curve, the above relation becomes an algebraic non linear equation in the three unknown parameters of the cell, $r, g, n$.

A first hand method of extracting the parameters from this equation might be to repeat the measure- ments at three different illumination levels for which the cell parameters remain practically constant. Then one would get the system of three equations $(i=1,2,3)$

$$
\begin{aligned}
\rho_{i}=\left(I_{\mathrm{sc}} / 2 V_{\mathrm{oc}}\right)_{i} \cdot r+ & \left(1 / V_{\mathrm{oc}}\right)_{i} \gamma \cdot n+ \\
& +\left(V_{\mathrm{oc}} / 2 I_{\mathrm{sc}}\right)_{i} \cdot g-\left(1 / I_{\mathrm{sc}}\right)_{i} \gamma \cdot g n .
\end{aligned}
$$

This can first be solved, by the usual methods of linear algebra, with respect to $n, g, g n$, in terms of the unknown $r$ and the constants $\rho_{i}$ 's; one obtains relations linear in $r$. Substituting the relations for $n$ and $g$ in the relation for $g n$ one finally gets a second degree algebraic equation in the unknown $r$. The solution of this latter determines $r$ and in turn $n$ and $g$.

\section{Conclusion.}

By looking at an old subject, as it were, from an unusual standpoint, the equation of the characteristic curve of a non-ideal solar cell could be given an explicit form. This made it possible to provide the theoretical background for the application of the area method to the measurement of both series and shunt resistances of the cell.

The experimental verification of the feasibility of this approach, especially as compared with other known methods [3], is a matter that the author cannot, at the present time, pursue.

\section{Acknowledgments.}

The advice provided by the unknown referees and the Scientific Supervision of the Journal is thankfully acknowledged.

[1] Araujo, G. L., Sanchez, E., IEEE Trans. Electron. Devices ED-29 (1982) 1511.

[2] Nguyen, P. H., Michel, C., Bottin, J., Revue Phys. Appl. 18 (1983) 775.

[3] Mialhe, P., Khoury, A., Charles, J. P., Phys. Status Solidi (a) 83 (1984) 403. 